\section{Consumer Horticulture Advancement: Identifying Critical Research Areas and Cultivating Collaborations}

\author{
Natalie Bumgarner ${ }^{1}$, Sheri Dorn ${ }^{2}$, Esther McGinnis ${ }^{3}$, \\ Pam Bennett ${ }^{4}$, Ellen Bauske ${ }^{5}$, Sarada Krishnan ${ }^{6}$, \\ and Lucy Bradley ${ }^{7}$
}

\begin{abstract}
ADDITIONAL INDEX WORDs. gardening, greenspace, health, nature, nutrition, wellbeing

Summary. Many fields of research converge to assess the impact of plants on human health, well-being, and nutrition. However, even with a recent history of horticulturists contributing to human-plant interaction work, much of the current research is conducted outside the context of horticulture and specifically outside of consumer horticulture $(\mathrm{CH})$. To connect $\mathrm{CH}$ to research being conducted by other disciplines that explore the role of plants in improving human quality of life, a workshop was held on 1 Aug. 2018 in Washington, DC, at the American Society for Horticultural Science (ASHS) annual conference. The workshop focused on current food science, nutrition, and crop-breeding efforts to enhance nutrition and flavor, and human health and well-being research related to nature and plant interactions in an increasingly urban population. Following these presentations regarding potential research linkages and collaboration opportunities, a facilitated discussion identified ways to improve future $\mathrm{CH}$ research and foster collaborative work. Action items identified included connecting research and vocabulary to help cultivate an interest in plants in younger generations; supporting awareness of collaborative opportunities with health, nutrition, urban planning, and public health practitioners; ensuring $\mathrm{CH}$ is known to administrators; and taking responsibility for initiating communication with colleagues in these areas.
\end{abstract}

$\mathrm{I}$

lluminating the many beneficial roles of plants in human lives, diets, and environments requires

Received for publication 30 May 2019. Accepted for publication 5 Sept. 2019.

Published online 7 November 2019.

${ }^{1}$ Plant Sciences Department, University of Tennessee, 2431 Joe Johnson Drive, 252 Ellington Plant Sciences, Knoxville, TN 37996

${ }^{2}$ Department of Horticulture, University of Georgia, 1109 Experiment Street, Griffin, GA 30223

${ }^{3}$ Department of Plant Sciences, North Dakota State University, P.O. Box 6050, Fargo, ND 58108

${ }^{4}$ Ohio State University Extension, Clark County, 3130 E. Main Street, Springfield, OH 45505

${ }^{5}$ Department of Plant Pathology, University of Georgia, 1109 Experiment Street, Griffin, GA 30223

${ }^{6}$ Denver Botanic Gardens, 1007 York Street, Denver, CO 80206

${ }^{7}$ Department of Horticultural Science, North Carolina State University, Campus Box 7609, Kilgore Hall 128, 2721 Founders Drive, Raleigh, NC 27695

This paper is based on the Workshop titled "The National Initiative for Consumer Horticulture: Identifying and Cultivating Consumer Horticulture Research Relationships" presented on 1 Aug. 2018 during the 2018 American Society for Horticultural Science annual conference in Washington, DC.

N.B. is the corresponding author. E-mail: nbumgarn@ utk.edu.

This is an open access article distributed under the CC BY-NC-ND license (https://creativecommons.org/ licenses/by-nc-nd/4.0/).

https://doi.org/10.21273/HORTTECH04422-19
Previous research focused on health and human issues in horticulture (HIH) and established the beneficial role of plants and the practice of horticulture in a range of therapeutic, educational, and workplace settings (Relf, 1992; Shoemaker et al., 1992; Ulrich, 1984; Waliczek and Zajicek, 1999). This period of horticulture research was built on both horticultural therapy and environmental psychology. Positive health and wellbeing benefits have been shown to reach varied populations, with effects on stress, productivity, attitude, concentration, and cognitive performance being documented (Lohr et al., 1996; Mooney and Nicell, 1992; Relf and Dorn, 1995; Shoemaker et al., 1992).

In recent years, $\mathrm{CH}$ scientists have played a more limited role in research fields outside horticulture, such as public health, that explore the impact of plants on people (Dorn et al., 2018). In light of the fact that $\mathrm{CH}$, by definition, focuses on "the cultivation, use, and enjoyment of plants, gardens, landscapes and related horticultural items to the benefit of individuals, communities, and the environment" (National Initiative for Consumer Horticulture, 2018), this relative lack of involvement merits intellectual consideration.

Today's science calls for integrated, collaborative research that brings together researchers with expertise in plant, nature, and health fields to promote human well-being and environmental sustainability within the context of increasingly urban populations. Interestingly, $\mathrm{CH}$ scientists, who focus on the science of plants as they relate to people, have not established consistent collaborations with social scientists or public health researchers, as evidenced by the few coauthorships in research journals outside horticulture (Dorn et al., 2018). Most $\mathrm{CH}$ scientists have been trained as plant scientists or production horticulturists, so partnering with agricultural or horticultural scientists to conduct research is a more natural fit. Although research collaborations in human nutrition and public health appear promising as a result of the increasing recognition and integration of plants and nature in human health and well-being studies (Hartig et al., 2014; Lohr, 2011), few CH scientists have developed research 
partnerships with social scientists outside the fields of horticulture.

A lack of understanding of the role of $\mathrm{CH}$ in social science fields may be explained, at least in part, by the general public's narrow view of the field. Doyle and Kelleher (2009) state that "limiting the term horticulture to the popularist understanding of just a gardening activity fails to encompass the enormity of the impact that horticulture has on individuals, communities, and society." Horticulture itself appears to be confronting an identity crisis because many plant enthusiasts, especially the young, do not connect their interest in plants with the practice of horticulture (Garden Media Group, 2014). Combined with this changing terminology is the challenge of plant blindness, which is the inability to see plants in our environments. First defined in a publication of the American Botanical Society (Wandersee and Schussler, 2001 ), this problem continues unabated, with even biological scientists struggling to identify common plants (Belkin, 2018). Consequently, it is hardly surprising that researchers outside of horticulture may not give full consideration to plants or the $\mathrm{CH}$ researchers whose expertise is based on interacting with plants and people.

To clarify and address specifically the scientific challenges and benefits of $\mathrm{CH}$ cooperation in wider humanplant fields of study, and to lay the foundation for developing current and future research partnerships, the $\mathrm{CH}$ and Master Gardener Professional Interest Group of the ASHS hosted a workshop and a facilitated discussion at the 2018 ASHS annual conference. The objective was to provide a review of relevant current research being conducted outside the realm of $\mathrm{CH}$, identify opportunities for collaboration, and determine potential $\mathrm{CH}$ contributions and benefits of $\mathrm{CH}$ inclusion.

\section{Materials and methods}

On 1 Aug. 2018 at the annual conference of the ASHS in Washington, DC, the $\mathrm{CH}$ and Master Gardener Professional Interest Group and the HIH Professional Interest Group cohosted a workshop. The title of the workshop was The $\mathrm{Na}$ tional Initiative for Consumer Horticulture: Identifying and Cultivating
Consumer Horticulture Research Relationships. About 20 extension specialists, professors, and graduate students attended. The objective of the workshop was to set the stage with a review of existing research, and then promote discussion, collaboration, and action.

Presentations explored potential research collaborations within as well as outside of agriculture. Dr. Esther McGinnis, Department of Plant Sciences, North Dakota State University, summarized food science, plant breeding, and human nutrition research efforts that could be expanded by working with $\mathrm{CH}$ scientists. Dr. Natalie Bumgarner, Plant Sciences Department, University of Tennessee, and Ms. Sheri Dorn, Department of Horticulture, University of Georgia, explored potential collaborative opportunities in human health and well-being. The workshop concluded with a facilitated discussion, led by Ms. Pam Bennett, Ohio State University Extension, on research needs, opportunities for collaboration, and next steps in connecting $\mathrm{CH}$ research with these areas within the context of efforts of the National Initiative for Consumer Horticulture (NICH). Individual presentations have been combined to avoid repetition and bring clarity to the results.

\section{Results \\ $\mathrm{CH}$ contributions to crop breeding, food science, and human nutrition research}

The consumer is often the end purchaser of fresh market vegetables; however, breeding and production efforts have focused on commercial producers' needs (Morris and Sands, 2006; Sands et al., 2009). Before the 21 st century, few vegetable breeding programs prioritized traits desired by consumers (such as enhanced nutrition or flavor), focusing instead on producer-valued traits such as yield, cost efficiency, and insect and disease resistance (Farnham and Grusak, 2014). Even commonly studied traits, such as shelf life, overlap with consumer needs, but do not have consumers as the primary audience.

Potato (Solanum tuberosum), the vegetable with the greatest consumption in the United States (Kaspar et al., 2013), is illustrative of the commercial production focus. During the 20th century, the overall goal of potato breeding was to make production and processing simpler and more profitable (Caligari, 1992). Potato breeding objectives included increased yield, decreased maturity time, tolerance to environmental stresses, tuber shape and color, storage longevity, processing characteristics, and resistance to common diseases (Caligari, 1992). Although these are all valuable and environmentally sustainable objectives, consumers' desires were secondary.

Low vegetable consumption should alarm the horticulture industry from both a public health and an economic perspective (Simon, 2014). Horticultural crops that are rich in antioxidants and phytonutrients can decrease the potential for chronic conditions such as diabetes, some cancers, and heart disease (Simon, 2014; Steinmetz and Potter, 1996). Despite vigorous marketing, the Centers for Disease Control estimate that fewer than $10 \%$ of Americans consume the recommended daily amount of vegetables (Lee-Kwan et al., 2017). The U.S. Department of Agriculture (2018) promoted vegetable consumption first with the food pyramid and now with increased emphasis on the "My Plate" plan, which encourages people to fill more than one-quarter of their plate with an array of colorful vegetables.

The potato industry began introducing cultivars with colorful skins and flesh that contain significantly greater levels of antioxidants compared with white-flesh potatoes. A recent study found that yellow- and purple-flesh potatoes contain more than double the level of phenolic compounds compared with whiteflesh potatoes (Kaspar et al., 2013). Purple-flesh potatoes have 20 times the level of anthocyanins compared with yellow potatoes. Yellow-flesh potatoes exhibit more than 45 times the level of carotenoids of white- and purple-flesh potatoes (Kaspar et al., 2013).

The question remains whether enhanced nutrition of colorful potato cultivars will result in increased consumer demand. Yukon Gold, a yellowflesh cultivar, has become popular for its gourmet cooking qualities, but the number of U.S. acres in production remains minimal (National Potato Council, 2018). Purple potato production is even less. Yellow and purple 
potatoes are usually sold as specialty products, such as mixtures of differentcolor baby potatoes.

The lack of consumer demand for yellow- and purple-flesh potatoes compared with white-flesh potatoes can be explained by a number of factors. White potatoes are more familiar to fresh-potato consumers (Kaspar et al., 2013). In addition, consumers ranked purple potatoes as having lower scores for aroma and appearance than yellow and white potatoes. However, the same consumer panel found that the overall flavor of yellow, purple, and white potatoes was not significantly different (Kaspar et al., 2013).

Many areas of research are required to support dietary changes, including plant breeding, human nutrition, and human aspects of adoption and awareness that link with $\mathrm{CH}$ efforts. Patil et al. (2014) have suggested amassing a team of scientists with backgrounds in plant breeding, human health, food science, and nutrition to address this issue. Bliss (1999) recommends a larger team that also includes social scientists and economists.

$\mathrm{CH}$ scientists may be able to help bridge the gap between specialty potato producers and consumers by educating the public and promoting consumption. Extension $\mathrm{CH}$ specialists could include these potatoes in home vegetable cultivar trials and in demonstration gardens, educating the public about these products and increasing the number of these cultivars routinely planted in home gardens. They can also reach out to the farmers' market growers and community-supported agriculture practitioners to produce these more nutritious cultivars. Marketing studies could be conducted to aid in the acceptance of nontraditional cultivars. Extension $\mathrm{CH}$ specialists often partner with extension food and nutrition specialists to educate the public about health benefits of food, and these efforts could be extended to these nutritious potatoes for best culinary effect.

Although nutritional content can be used to promote vegetable consumption, flavor is equally important, if not more so, to consumers (Simon, 2014). An unexpected source has sparked a resurgence in vegetable flavor research and sensory evaluation. Chef Dan Barber, owner of Blue Hill at Stone Barns in Pocantino Hills, NY, sponsored a chef and breeder summit in 2013 with the goal of working together to produce high-yielding and flavorful vegetables (Beans, 2017). Barber has collaborated with Cornell University vegetable breeder Dr. Michael Mazourek to produce a delicious new winter squash (Cucurbita moschata): 'Honeynut' (Whitney, 2017). This unique collaboration used advanced culinary techniques, such as dry roasting to caramelize the sugars in the squash, before being evaluated for flavor. Previously, Dr. Mazourek's team microwaved or steamed sensory samples, which were cooking techniques that did not enhance vegetable flavor.

Not every interdisciplinary vegetable team can tap into the expertise and resources of a celebrity chef to evaluate new cultivars. However, $\mathrm{CH}$ scientists can reach out to local chefs, farmers' market producers, and public panels (Beans, 2017). Such input can help vegetable breeders, at the early stages, to prioritize which traits matter to consumers and then to guide the breeding process (Hayes, 2016).

Through interaction with consumer audiences, $\mathrm{CH}$ has a powerful potential to connect breeding and nutrition advancements with research focused on consumer perception, preference, and adoption. Previous and recent studies that were summarized in two comprehensive review articles suggest that gardening can increase consumption of fruits and vegetables in youth in general (Savoie-Roskos et al., 2017), and encourage eating a broader range of vegetables species (Langellotto and Gupta, 2012). This increase can also extend into adulthood. A recent study showed that childhood and adolescent gardening experiences led to greater consumption of fruits and vegetables by college freshmen compared with those who had never gardened (Loso et al., 2018). $\mathrm{CH}$ scientists can contribute to this research by supplying consumer input to crop breeding and selection efforts, and by collaborating with nutrition and social scientists to investigate and enhance adoption and acceptance of new crops and cultivars to support both horticultural science and human health and well-being.

\section{$\mathrm{CH}$ contributions to health and well-being research}

The field of $\mathrm{CH}$ should be committed to forming research collaborations that enable $\mathrm{CH}$ scientists to contribute more consistently to current research focusing on the interaction of humans, plants, and natural or green environments. This work often encompasses a wide range of expertise, including environmental psychology, urban planning, landscape architecture and design, public health, and social science. However, unlike previously cited work that was initiated by horticulturists, much of this research is currently conducted outside the horticulture field and without the input of $\mathrm{CH}$ scientists (Dorn et al., 2018). CH research and input may clarify the context of the work, contribute to the design and methodology, and facilitate authentic human interaction. $\mathrm{CH}$ scientists could bring much-needed expertise to these studies.

CONTEXTUALIZING THE RESEARCH. Researchers who work in the humanplant-nature arena but were trained in fields outside horticulture often publish using "nature" and "natural" terminology that includes both natural and built environments and does not always exclude artificial elements (Hartig et al., 2014). An example of this terminology challenge is the current debate about the inclusion of film, video, or images of nature, as well as the use of artificial plants, in nature research (van den Berg and van den Berg, 2015). Published works often lack clear articulation of the specific plants or the environment in which they are located (Keniger et al., 2013). These factors impact both where and how research results are interpreted and applied.

It is not uncommon for there to be a lack of distinction made among plant species, plant or ecosystem maturity, and management intensity. This often-insufficient inclusion of ecology or horticulture expertise has led to incomplete understanding of the role of biodiversity, species richness, and composition of plants in such settings (Keniger et al., 2013). Thompson (2011) described this perspective from the field of landscape and urban planning, and concluded that specific characteristics of the 
landscape-quantity, proximity, and access-can be critical to providing consistent or repeatable health benefits for different populations and are needed for proper valuation. As an example of the potential for ambiguity in describing the quality, quantity, or even presence of plants, Lee and Maheswaran (2010) used "greenspace" and "public open space" interchangeably in their review, while reporting weak evidence of health benefits of urban greenspace. Likewise, Cameron (2014) argues that the interactions between human health and vegetation are weak, citing the limited information about the form, extent, or quality of vegetation studied.

The lack of clear definitions of the environments in which humanplant-nature interactions take place also diminishes the opportunity to explain the specific mechanisms of effect (Keniger et al., 2013; Thompson, $2011)$. The value of clarity and precision in describing plants and environments while conducting research was presented concisely by van den Berg and van den Berg (2015) in a summary from a People Plant Council Symposium. These researchers stated that "only studies that directly relate exposure to plants and greenspaces to health outcomes should be admitted into the evidence base."

Although such models and mechanisms for plant and human interaction are not always described in public health fields, horticultural therapy and related fields have focused on models in terms of activities, roles, and benefits (Relf, 2008; Son et al., 2016). Likewise, $\mathrm{CH}$ researchers are most often trained in plant sciences, but also function daily across two spectra that describe human-plant interaction: level of engagement and level of cultivation. This relationship is defined across a range of settings and professional areas, as shown in Fig. 1. The level of cultivation on the $x$-axis relates to the range of environments in which humans can interact with plants. At one end of the spectrum are wilderness areas, where no control has been exerted; at the other end of that axis is the very controlled use of plants in constructed environments, such as indoor foliage plants. The level of engagement on the $y$ axis relates to the degree to which formalized practices structure the interaction of people and plants. Formal medical care resides at one end of the spectrum whereas incidental, unintentional plant interaction anchors the other.

The space occupied within each quadrant defines the specific humanplant interaction. As examples of the importance of the context of humanplant research, "A" occupies a position that could describe a rehabilitation program conducted by a horticultural therapist in a nursing home, whereas " $B$ " could represent a therapeutic gardening program led by an extension master gardener volunteer in a community garden. The $C$ position could represent an apartment resident visiting a rooftop garden whereas the $\mathrm{D}$ position could be a bicyclist riding through a city with an urban tree canopy. The potential human benefit from plant interaction in each of these settings could differ because of the level of human engagement in the experience and the type, location, and level of cultivation of the plants themselves. In each of these examples, the training and experience of $\mathrm{CH}$ scientists could be an asset to a research team by providing context and clarity of the mechanism and impact of human-plant-nature activities.

Facilitating aUthentic AND REPLICABLE INTERACTIONS AMONG PEOPLE, PLANTS, AND NATURE. The act of cultivating plants is an integral component of human-plant interactions. Many fields of research outside horticulture have explored multiple methodologies (e.g., views of nature, pictures, walks in urban settings, and physical activity in natural settings) (Cameron, 2014), but largely ignored the physical act of gardening. The effect of contact with "gardened" nature vs. "wild" nature is rarely investigated by environmental psychologists (Kendle and Stoneham, 2014). Examples A, B, and C as shown in Fig. 1 all illustrate human contact with

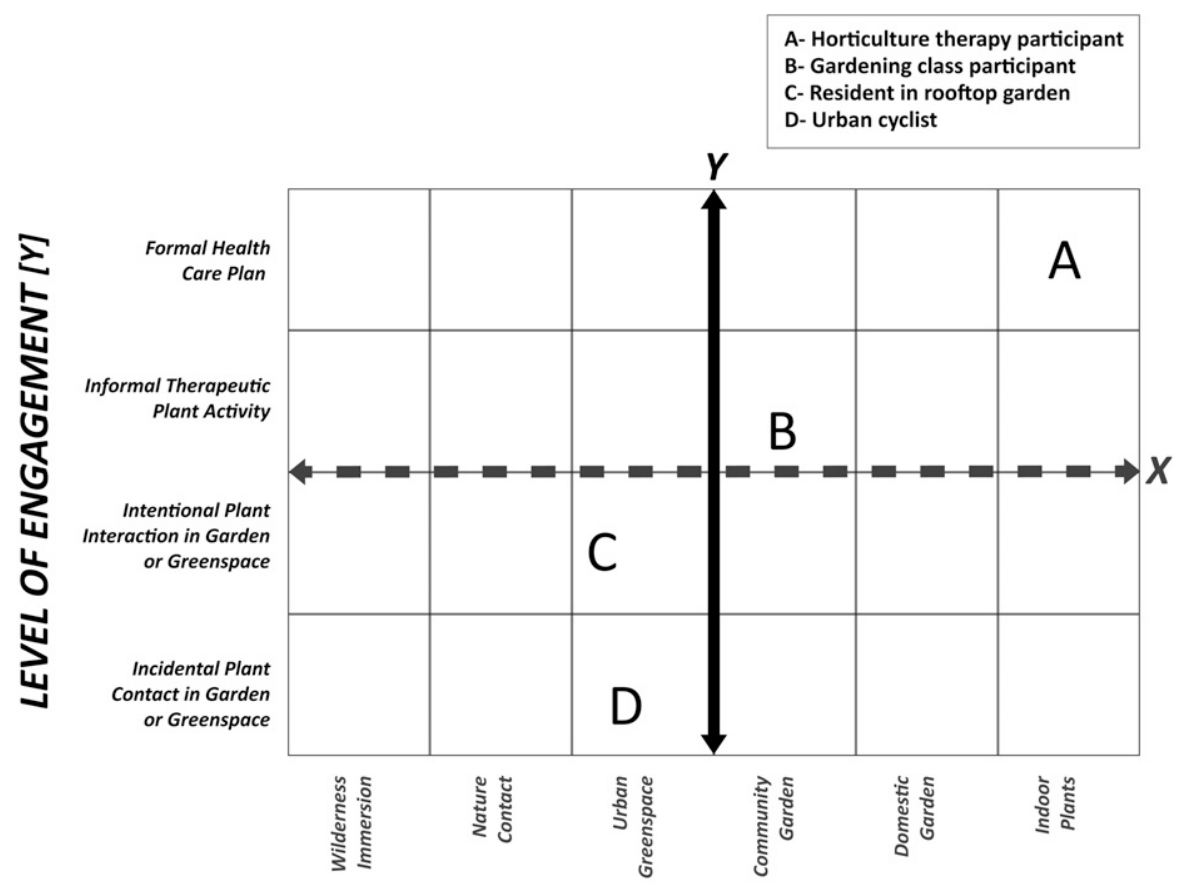

LEVEL OF CULTIVATION [X]

Fig. 1. Context of human-plant relationships explained through defining the $(x-$ axis) level of cultivation and the ( $y$-axis) level of engagement. Letters represent different combinations of cultivation and engagement common in consumer horticulture. " $A$ " occupies a position that could describe a horticulture therapy plan of treatment conducted by a horticultural therapist whereas " $B$ " could represent a therapeutic gardening program led by an Extension Master Gardener. The $\mathrm{C}$ position could represent an apartment resident visiting a rooftop garden whereas the $D$ position could be a bicyclist riding through a city with an urban tree canopy. 
"gardened" nature and include the physical act of gardening. As shown in Fig. 1, these "gardened" settings occupy a large percentage of the potential contact of humans with plants in our urban world. $\mathrm{CH}$ scientists are uniquely suited to explore the impacts of this contact.

When physical, mental, social, and nutritional benefits are attributed to "nature" or "greenspace," this blurs and diminishes the importance of gardening. Actively working with plants in the garden or landscape provides a range of social and health benefits that would not necessarily accrue when simply observing nature (Cameron, 2014).

A clear understanding of the separate and interacting effects of "nature" and "garden" is crucial to conducting and using human-plant research, especially in an increasingly urban world. Although horticulture researchers have investigated gardening impacts in many venues for decades (Relf and Lohr, 2003), this emphasis is often lacking elsewhere. Although limited in public health and other fields, the research published in this area is intriguing. For example, domestic gardens in most urban settings had a mitigating effect on local health deprivation that was greater than parks and communal green space (Dennis and James, 2017). Interestingly, this research suggests that investments in domestic garden space may be more beneficial than parks and communal greenspace in populated areas.

Although the value of human interaction with plants can be overlooked in human-nature studies, it is the foundation of horticultural science. $\mathrm{CH}$ scientists could help design research that includes a focus on the value of actively cultivating plants (Dorn et al., 2018; Kendle and Stoneham, 2014). Current human-plant research conducted outside horticulture may also be designed in a way that lacks authentic horticultural experience, focusing instead on passive visual observation (South et al., 2018).

Full inclusion of horticulturists in the design of research experiments in other disciplines, such as environmental psychology, public health, and urban planning, would allow exploration of the potentially varied effects of plant management and plant contact via green environments. de Vries et al.
(2003) noted, "Maybe the mechanisms behind both effects, that of a garden and greenspace, are different." This concept is familiar to horticulturists and has been foundational to previously published work (Langellotto and Gupta, 2012), but is not always considered in research led by other experts. When horticulture is added as an afterthought, $\mathrm{CH}$ specialists are able to help with methodology of gardening, but are unable to contribute to the underlying premise of the research.

CONTRIBUTING TO THE RESEARCH DESIGN AND METHODOLOGY. Horticultural activities, such as design, plant selection, and maintenance, may improve the health potential of urban green spaces because these activities improve the quality of the "greenery" (Cameron, 2014). CH scientists can guide critical research design decisions, including plant selection, maintenance, identification of horticultural tasks for research treatments, and selection of seasonally appropriate elements.

Knowledge of $\mathrm{CH}$ may also help remove or reduce uncontrolled research variables. For example, sunloving plants, installed in shaded, therapeutic gardens may require frequent pesticide applications that can be detrimental to patient health. "With healthcare professionals in charge of garden maintenance, the necessary expertise and vision to maintain plantings in keeping with original therapeutic goals may be missing" (Davis, 2011). However, engaging horticulturists at the design stage could avoid critical design flaws. Horticulturists have the necessary knowledge of plants to reduce potential risks and negative health effects associated with plants (i.e., pollen generation, hazards from falling limbs and debris) (van den Bosch and Nieuwenhuijsen, 2017).

Knowledge of $\mathrm{CH}$ may also result in the incorporation of additional treatments or methodologies that enhance the impact of the study. For example, recent research on the effects of a community green intervention included site cleanup and grading, planting of turf and trees, fence installation, and the conduct of ongoing maintenance (South et al., 2018). Human benefits were assessed after this work was completed, but the project did not engage community residents in the activities. $\mathrm{CH}$ scientists experienced in volunteerism and practical gardening may have included a hands-on gardening component. Personal participation in the effort could enhance benefit, as Kuo and Sullivan (2001) have suggested.

Public health researchers commonly use cross-sectional population data, observational data, or selfreported measures in longitudinal studies, so there may be confounding factors or bias in sampling (Hartig et al., 2014; Keniger et al., 2013). Although correlational work can be an excellent way to refine studies and hypotheses, experimental work is also needed to clarify mechanisms, questions of proximity, and a pathway for implementation. Experimental research, in which most plant scientists and horticulturists are trained, is designed to eliminate the opportunity for uncontrolled factors to affect results. Through horticultural knowledge of plant materials and training in experimental research, $\mathrm{CH}$ scientists can be ideal collaborators on research that translates observationally derived hypotheses into experimental studies. However, experimental studies have limitations in extrapolating what short-term effects of treatments might mean through time (Hartig et al., 2014). In investigating complex health questions, all research methodologies can have weaknesses (Hartig et al., 2014), but teams of cross-disciplinary researchers can be best positioned to balance the strengths and weaknesses of their different fields of training and research experience to answer questions most effectively.

\section{Workshop-facilitated discussion: Connecting $\mathrm{CH}$ to allied research areas}

Several important points were made during the discussions. Participants immediately noted that scarcity of faculty positions in $\mathrm{CH}$ is currently a key hurdle to expanding the research impact of $\mathrm{CH}$. In addition, extension or outreach focus, rather than research, dominates many current faculty positions.

Limited consumer awareness of horticultural research developments and the subsequent slow adoption of current research advances present a challenge, such as for breeding efforts 
addressing human nutrition. These useful advances face a headwind of market momentum as a result of the familiarity of current cultivars that can cause a drag on future work if new cultivar introductions are unsuccessful in attaining acceptable market share.

Horticulture seems to be facing an identity crisis. This is not a crisis of interest, utility, or applicability, but rather of an understanding of horticulture as a profession as well as its scientific value beyond production. Familiarity with and understanding of horticulture are extremely low. Incorporating new vocabulary that connects with audiences will likely be more effective than trying to educate our audiences on our disciplinary terminology. It is important to connect research in horticultural science with key areas of consumer interest, such as recent commercial demand for interior plants, fueled by younger generations.

It is essential that $\mathrm{CH}$ scientists open doors to collaborations with medical, public health, and nutrition experts. This can be accomplished by ensuring that university administrators are aware of $\mathrm{CH}$ research and outreach efforts, and by building personal relationships in informal settings across our universities. Building on previous research that often presents observational or correlational data and uses imprecise terminology is challenging. It may be easier to build collaborations with emerging and early-stage researchers in allied fields. Although CH scientists clearly see the collaboration benefits in research investigating human-plant-nature interactions, it is clear that it will be largely our responsibility to push to expand our research into research areas outside the field of horticulture.

\section{Discussion}

The potential contribution of $\mathrm{CH}$ scientists and educators to research projects has yet to be fully explored because few examples of cross-disciplinary teams including horticulturists are documented in literature outside horticulture (Dorn et al., 2018; Keniger et al., 2013). Lead researchers for large multidisciplinary research projects focused on medicine, nutrition, or public health often reside in other departments and colleges, as noted by Bratman et al. (2015a), de Boer et al. (2017), Dennis and James (2017), and Locke et al. (2017). Smaller roles in initial collaborations may be required to create a foundation to ensure $\mathrm{CH}$ methodology integrating authentic human interaction with plants is used and valued as a precursor to larger roles in future work. We need to avail ourselves to play a range of roles in research opportunities outside our agricultural or horticultural fields to create a platform from which we educate our colleagues on ways our expertise can benefit larger projects. This will allow us to build capacity to contribute at a greater level.

The burden of initiation lies with $\mathrm{CH}$ scientists. Change will occur as we reach out to other fields and document our ability to contribute to rigorous science and the beneficial application of such research within our societies. Through their broad range of activities and interaction with the general population (Bauske et al., 2014, 2015), CH scientists are well positioned to build on previous efforts focused on human-plant research and initiate new collaborations with social, health, and environmental scientists, providing context for the many roles of plants in human lives and societies. They can address the limitations inherent when humanplant interaction and impacts are studied and reported without the engagement of those trained in the use of plants in landscapes, gardens, and human environments.

Two organizations have been created to address the combination of research, industry, and educational impacts of plant blindness in our society. The first is Seed Your Future, which brings together members of the horticulture industry, educators, nonprofits, interested individuals, and garden organizations, along with public gardens. This organization created a campaign to excite young people about the power of plants (Wright, 2018).

A second organization, $\mathrm{NICH}$, is a national consortium of industry leaders working to create a common voice to promote the benefits of plants, gardens, and landscapes, and to increase the value of the $\$ 196$ billion industry that provides jobs for an estimated 2 million people (Bauske et al., 2015; Dorn et al., 2018; Hodges et al., 2015). Begun in 2012, this effort has grown into an extensive collaboration of professionals from colleges and universities, public gardens, nonprofit organizations, associations, government, extension, and the green industry. The NICH mission is to grow a healthy world through plants, gardens, and landscapes, primarily by increasing the percentage of U.S. households that practice indoor or outdoor gardening (NICH, 2018). $\mathrm{NICH}$ is tasked with integrating the efforts of $\mathrm{CH}$ scientists, educators, $\mathrm{CH}$ commercial enterprises, and experienced "plant people" (Bradley et al., 2016).

Now is the time to address this gap in consumer awareness and value of $\mathrm{CH}$. Rapid urbanization is increasing the pressure for horticulturists to address the needs of urban populations, including a fresh and nutritious food supply as well as the training and skills necessary to implement urban horticulture solutions for human health and well-being (Lohr and Relf, 2014). Horticulture's view of itself as operating mainly in the agricultural production realm needs to change if we are to broaden our impact on society. We need to augment our agricultural identity by connecting with physical, social, economic, and environmental health scientists focused on urban, suburban, and rural populations.

\section{Literature cited}

Bauske, E.M., G.R. Bachman, T. Bewick, L. Bradley, R. Durham, and M.H. Meyer. 2015. The case for a strategic plan for consumer horticulture research, education and extension. HortTechnology 25:477-479.

Bauske, E.M., G.R. Bachman, L. Bradley, K. Jeannette, A.S. O'Connor, and P.J. Bennett. 2014. Consumer horticulture outreach: Communication challenges and solutions. HortTechnology 24:266-269.

Beans, C. 2017. Science and culture: Vegetable breeders turn to chefs for flavor boost. 7 Oct. 2018. <http://www.pnas. org/content/114/40/10506>.

Belkin, D. 2018. Rhododendron? Hydrangea? America doesn't know anymore. 6 Jan. 2019. <https://www.wsj.com/articles/ rhododendron-hydrangea-america-doesntknow-anymore-1534259849>.

Bliss, F.A. 1999. Nutritional improvement of horticultural crops through plant breeding. HortScience 34:1163-1167. 
Bowler, D.E., L.M. Buyung-Ali, T.M. Knight, and A.S. Pullin. 2010. A systematic review of evidence of the added benefits to health of exposure to natural environments. BMC Public Health 10:456-465.

Bradley, L., E.M. Bauske, T.A. Bewick, J.R. Clark, R.E. Durham, G. Langellotto, M.H. Meyer, M. Pooler, and S. Dorn. 2016. Developing a national strategic plan for consumer horticulture. HortTechnology 26:372-378.

Bratman, G.N., G.C. Daily, B.J. Levy, and J.J. Gross. 2015a. The benefits of nature experience: Improved affect and cognition. Landsc. Urban Plan. 138:41-50.

Bratman, G.N., J.P. Hamilton, K.S. Hahn, G.C. Daily, and J.J. Gross. 2015b. Nature experience reduces rumination and subgenual prefrontal cortex activation. Proc. Natl. Acad. Sci. USA 112:8567-8572.

Bringslimark, T., T. Hartig, and G.G. Patil. 2009. The psychological benefits of indoor plants: A critical review of the experimental literature. J. Environ. Psychol. 29:422-433.

Caligari, P.D.S. 1992. Breeding new varieties, p. 334-372. In: P.M. Harris (ed.). The potato crop: The scientific basis for improvement. 2nd ed. Springer, Dordrecht, The Netherlands.

Cameron, R.W.F. 2014. Health and wellbeing, p. 1001-1023. In: G.R. Dixon and D.E. Aldous (eds.). Horticulture: Plants for people and places. Springer Science Media, Dordrecht, The Netherlands.

Davis, B.E. 2011. Rooftop hospital gardens for physical therapy: A post-occupancy evaluation. Health Environ. Res. Design J. 4:14-43.

de Boer, B., J.P. Hamers, S.M. Zwakhalen, F.E. Tan, H.C. Beerens, and H. Verbeek. 2017. Green care farms as innovative nursing homes, promoting activities and social interaction for people with dementia. J. Amer. Medical Directors Assn. 18:4046

Dennis, M. and P. James. 2017. Evaluating the relative influence on population health of domestic gardens and green space along a rural-urban gradient. Landsc. Urban Plan. 157:343-351.

de Vries, S., S. van Dillen, P.P. Groenewegen, and P. Spreeuwenberg. 2013. Streetscape greenery and heath: Stress, social cohesion, and physical activity as mediators. Soc. Sci. Med. 94:26-33.

de Vries, S., R.A. Verheij, P.P. Groenewegen, and P. Spreeuwenberg. 2003. Natural environments-healthy environments? An exploratory analysis of the relationship between greenspace and health. Environ. Plan. 35:1717-1731.

Dorn, S., L. Bradley, D. Hamrick, J. Weisenhorn, P. Bennett, J. Callabro, B. Behe, E. Bauske, and N. Bumgarner. 2018. The National Initiative for Consumer Horticulture: Focusing on the critical role of communication and collaboration to further research, extension, and industry goals. HortTechnology 28:414-421.

Doyle, O.P.E. and Y. Kelleher. 2009. Rediscovering horticulture: An exploration from plant production to social capital. Acta Hort. 817:209-216.

Farnham, M.W. and M.A. Grusak. 2014. Assessing nutritional changes in a vegetable over time: Issues and considerations. HortScience 49:128-132.

Garden Media Group. 2014. What the millennial generations wants from YOU, the garden industry. I July 2019. <http:// grow.gardenmediagroup.com/bid/ $349849 /$ What - the - MillennialGeneration-Wants-from-YOU-theGarden-Industry>.

Goldman, I.L. 2014. The future of breeding vegetables with human health functionality: Realities, challenges, and opportunities. HortScience 49:133-137.

Hansson, S.O., P. Aman, W. Becker, D.J. De Koning, C.J. Lagerkvist, I. Larsson, A. Lehrman, U. Riserus, and S. Stymne. 2018. Breeding for public health: A strategy. Trends Food Sci. Technol. 80:131-140.

Hartig, T., R. Mitchell, S. de Vries, and H. Fromkin. 2014. Nature and health. Annu. Rev. Public Health 35:207-228.

Hayes, M. 2016. Plant breeders take cues from consumers to improve kale. 8 Oct. 2018 . <http://news.cornell.edu/ stories $/ 2016 / 11 /$ plant-breeders-takecues-consumers-improve-kale>

Hodges, A.W., C.R. Hall, M.A. Palma, and H. Khachatryan. 2015. Economic contributions of the green industry in the United States in 2013. HortTechnology 25:805-814.

Kaplan, R. and S. Kaplan. 1989. The experience of nature: A psychological perspective. Cambridge University Press, New York, NY.

Kaspar, K.L., J.S. Park, C.R. Brown, K. Weller, C.F. Ross, B.D. Mathison, and B.P. Chew. 2013. Sensory evaluation of pigmented flesh potatoes (Solanum tuberosum L.). Food Nutr. Sci. 4:77-81.

Kendle, T. and J. Stoneham. 2014. Horticulture and society, p. 953-964. In: G.R. Dixon and D.E. Aldous (eds.). Horticulture: Plants for people and places.
Springer Science Media, Dordrecht, The Netherlands.

Keniger, L.E., K.J. Gaston, K.N. Irvine, and R.A. Fuller. 2013. What are the benefits of interacting with nature? Intl. J. Environ. Res. Public Health 10:913-935.

Kuo, F.E. and W.C. Sullivan. 2001. Environment and crime in the inner city: Does vegetation reduce crime? Environ. Behav. 33:343-367.

Langellotto, G.A. and A. Gupta. 2012. Gardening increases vegetable consumption in school-aged children: A meta-analytical synthesis. HortTechnology 22:430-445.

Lee, A.C.K. and R. Maheswaran. 2010. The health evidence of urban green spaces: A review of the evidence. J. Public Health 33:212-222.

Lee-Kwan, S.H., L.T. Moore, H.M. Blanck, D.M. Harris, and D. Galuska. 2017. Disparities in state-specific adult fruit and vegetable consumption-United States, 2015. Morb. Mortal. Wkly. Rep. 66:1241-1247.

Locke, D.H., S. Han, M.C. Kondo, C. Murphy-Dunning, and M. Cox. 2017. Did community greening reduce crime? Evidence from New Haven, CT, 19962007. Landsc. Urban Plan. 161:72-79.

Lohr, V.I. 2011. Greening the human environment: The untold benefits. Acta Hort. 916:159-169.

Lohr, V.I., C.H. Pearson-Mims, and G.K. Goodwin. 1996. Interior plants may improve worker productivity and reduce stress in a windowless environment. J. Environ. Hort. 14:97-100.

Lohr, V.I. and P.D. Relf. 2000. An overview of the current state of human issues in horticulture in the United States. HortTechnology 10:27-33.

Lohr, V.I. and P.D. Relf. 2014. Horticultural science's role in meeting the need of urban populations, p. 1047-1086. In: G.R. Dixon and D.E. Aldous (eds.). Horticulture: Plants for people and places. Springer Science Media, Dordrecht, The Netherlands.

Loso, J., D. Staub, S.E. Colby, M.D. Olfert, K. Kattelmann, M. Vilar, J. Colee, W. Zhou, L. Franzen-Castle, and A.E. Matthews. 2018. Gardening experience is associated with increased fruit and vegetable intake among first-year college students: A cross-sectional examination. J. Acad. Nutr. Diet. 118:275-283.

Mooney, P. and P.L. Nicell. 1992. The importance of exterior environment for Alzheimer's residents: Effective care and risk management. Health Care Mgt. Forum 5:23-29. 
Morris, C.E. and D.C. Sands. 2006. The breeder's dilemma: Yield or nutrition? Nat. Biotechnol. 24:1078-1080.

National Initiative for Consumer Horticulture. 2018. Definition and core values. 6 Jan. 2019. <https://consumerhort. org $>$.

National Potato Council. 2018. Potato statistical yearbook. 7 Oct. 2018. <http:// nationalpotatocouncil.org/files/8415/ $3315 / 3604 / 2018$ _NPC_Statistical_ Yearbook.pdf>.

Patil, B.S., K. Crosby, D. Byrne, and K. Hirschi. 2014. The intersection of plant breeding, human health, and nutritional security: Lessons learned and future perspectives. HortScience 49:116-127.

Relf, D. 1990. Psychological and sociological response to plants: Implications for horticulture. HortScience 25:11-13.

Relf, P.D. 1992. Human issues in horticulture. Hort Technology 2:159-171.

Relf, P.D. 2008. Historical perspective on theoretical models for research and program development horticultural therapy. Acta Hort. 775:79-91.

Relf, P.D. and S. Dorn. 1995. Horticulture: Meeting the needs of special populations. Hort Technology 5:94-103.

Relf, P.D. and V.I. Lohr. 2003. Human issues in horticulture. HortScience 38:984 993.

Sands, D.C., C.E. Morris, E.A. Dratz, and A.L. Pilgeram. 2009. Elevating optimal human nutrition to a central goal of plant breeding and production of plant-based foods. Plant Sci. 177:377-389.

Savoie-Roskos, M.R., H. Wengreen, and C. Durward. 2017. Increasing fruit and vegetable intake among children and youth through gardening-based interventions: A systematic review. J. Acad. Nutr. Diet. 117:240-250.

Shoemaker, C.A., K. Randle, P.D. Relf, and E.S. Geller. 1992. Relationships between plants, behavior, and attitudes in an office environment. HortTechnology 2:205206.

Simon, P.W. 2014. Progress toward increasing intake of dietary nutrients from vegetables and fruits: The case for a greater role for the horticultural sciences. HortScience 49:112-115.

Son, K.C., S.J. Jung, A.Y. Lee, and S.A. Park. 2016. The theoretical model and universal definition of horticultural therapy. Acta Hort. 1121:79-88.

South, E.C., C.H. Bernadette, M.C. Kondo, J.M. MacDonald, and C.C. Branas. 2018. Effect of greening vacant land on mental health of community-dwelling adults: A cluster randomized trial. J. Amer. Medical Assn. Network Open 1:14.

Steinmetz, K.A. and J.D. Potter. 1996. Vegetables, fruit, and cancer prevention: A review. J. Amer. Dietetics Assn. 96:10271039.

Thompson, C.W. 2011. Linking landscape and health: The recurring theme. Landsc. Urban Plan. 99:187-195.
Ulrich, R.S. 1984. View through a window many influence recovery from surgery. Science 224:420-421.

U.S. Department of Agriculture. 2018. Choose my plate. 5 Oct. 2018. <https:// choosemyplate.gov>.

van den Berg, A.E. and M.M.H.E. van den Berg. 2015. Health benefits of plants and green space: Establishing the evidence base. Acta Hort. 1093:19-30.

van den Bosch, M. and M. Nieuwenhuijsen. 2017. No time to lose: Green the cities now. Environ. Intl. 99:343-350.

Waliczek, T.M. and J.M. Zajicek. 1999. School gardening: Improving environmental attitudes of children through hands-on learning. J. Environ. Hort. 14:204-209.

Wandersee, J. and E. Schussler. 2001. Toward a theory of plant blindness. Plant Sci. Bull. 47:2-9.

Whitney, A. 2017. Honeynut squash is a tiny squash with a big history. 7 Oct. 2018. <https://www.bonappetit.com/ story/honeynut-squash-history $>$.

Wright, J. 2018. Seed Your Future is greenhouse grower's first ever gamechanger of the year. 6 Jan. 2018. <https://www. greenhousegrower.com/events/seed-yourfuture-is-greenhouse-growers-first-evergamechanger-of-the-year/>. 